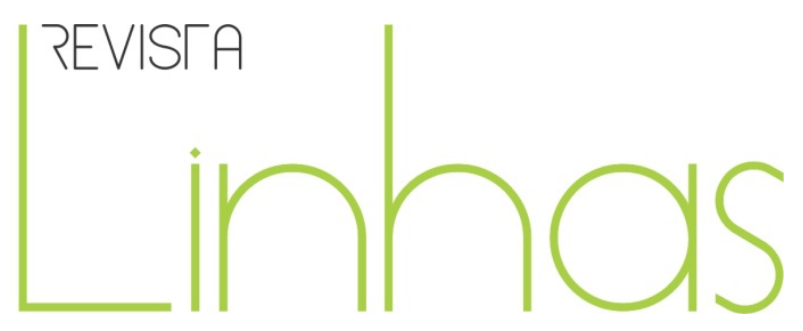

\title{
Resenha do livro Vozes do Bolsa Família: autonomia, dinheiro e cidadania
}

REGO, Walquiria Leão e PINZANI, Alessandro. Vozes do Bolsa Família: autonomia, dinheiro e cidadania. 2 ed. São Paulo: Unesp, 2014.

\section{Tatiana Pires Escobar}

Doutoranda em Educação pela Universidade Federal de Santa Catarina - UFSC - Brasil tatiana.escobar@hotmail.com

\section{Julia Siqueira da Rocha}

Doutoranda em Educação pela Universidade Federal de Santa Catarina - UFSC - Brasil jsiqueiradarocha@gmail.com

\section{Ione Ribeiro Valle}

Pós-doutora pela École des Hautes Études en Sciences Sociales - Paris

ione.valle@ufsc.br

\section{Para citar esta resenha:}

ESCOBAR, Tatiana Pires; ROCHA, Julia Siqueira da; VALLE, Ione Ribeiro. Resenha do livro Vozes do Bolsa Família: autonomia, dinheiro e cidadania. Revista Linhas. Florianópolis, v. 16, n. 31, p. 325-330, maio/ago. 2015.

\section{DOI: $10.5965 / 1984723816312015325$}

http://dx.doi.org/10.5965/1984723816312015325 
O livro Vozes do Bolsa Família - autonomia, dinheiro e cidadania, de Walquiria Domingues Leão Rego e Alessandro Pinzani ${ }^{1}$, publicado em 2013 pela Editora da Unesp, contribui no processo de organização das vozes daqueles historicamente silenciados nas pesquisas acadêmicas. Estruturalmente, a obra tem prefácio, introdução, cinco capítulos e considerações finais. Os capítulos têm por título sequencialmente: Ouvir a voz dos pobres; Bases teóricas da pesquisa; As entrevistas; Pobreza um conceito pluridimensional; e Dinheiro e autonomia.

No capítulo introdutório, os pesquisadores expõem a tese principal do trabalho, e informam os caminhos a serem delineados no percorrer do livro. Afirmando que "a renda regular em dinheiro é um importante instrumento de autonomia individual e política" (REGO; PINZANI, 2013, p. 20), eles se propõem a investigar os efeitos políticos e morais na vida e nas individualidades de beneficiários do Programa Bolsa Família. Para tal, realizaram durante cinco anos viagens de pesquisa nas regiões mais pobres e tradicionalmente desamparadas do Brasil, e nestas localidades entrevistaram mulheres que vivem em estado de extrema pobreza material e, também, na maior parte dos casos, de submissão de gênero e familiar.

No capítulo 1, os autores apresentam a perspectiva teórica e ética que fundamentou a escolha metodológica de ouvir a voz dos pobres. Expõem que a leitura da atividade empírica foi inspirada na perspectiva da Teoria Crítica. Neste sentido, traçam seus estudos a partir do pressuposto de que não há modelos ideais de sociedade e salientam, dentro do escopo desta corrente de pensamento, as contribuições de Adorno e Horkheimer para a fundamentação crítica da sociedade capitalista. Considerando que o uso da Teoria deve estar amarrado aos resultados empíricos das ciências sociais, os autores desenham seu estudo a partir do confronto entre as experiências de injustiças, relatadas pelas entrevistadas e os ideais/valores dominantes na sociedade, desvelando, desta forma, as tensões e contradições entre esses domínios.

Os autores indicam no capítulo 2 suas referências normativas, a saber: (1) um nível

\footnotetext{
${ }^{1}$ Walquiria Domingues Leão Rego é professora titular de Teoria Social do Instituto de Filosofia e Ciências Humanas da Unicamp. Alessandro Pinzani é professor de Ética e Filosofia Política na Universidade Federal de Santa Catarina.
} 
básico de autonomia moral e individual; e (2) o desenvolvimento de uma percepção de si como membro de uma comunidade política mais ampla (REGO; PINZANI, 2013, p. 38). No constructo teórico dos fios condutores, observa-se o esforço de manter um diálogo entre o aspecto da autonomia e da cidadania, sem demarcações epistemológicas, mas compreendendo que eles se entrelaçam na corrente da vida social. Neste sentido, a autonomia individual, em grau mínimo, é vista sobre aspectos múltiplos, entre eles, como a capacidade do sujeito de agir conforme um projeto pessoal de vida boa, considerando "direitos e deveres com base em princípios universais e não locais ou sociais" (REGO; PINZANI, 2013, p. 57).

A relação entre renda monetária e autonomia individual está no cerne dos apontamentos teóricos dos autores, considerando o engendramento do sistema econômico capitalista em que não há possibilidade de oferecer de forma igualitária os instrumentos mínimos para o exercício da cidadania e autonomia individual.

Desta forma, o quadro de pobreza em que vivem as mulheres entrevistadas por Rego e Pinzani se caracteriza, claramente, como um obstáculo ao desenvolvimento de autonomia plena. No campo subjetivo, como entrave à autonomia, estão as condições de humilhação em que vivem os pobres do país, fenômeno derivado do medo do parasitismo típico da moderna sociedade capitalista, em que há um valor moral absoluto atribuído ao trabalho, em que são consideradas vergonhosas as condições de desemprego, dependência econômica e necessidade de auxílio governamental para garantia da subsistência. Estes valores são compartilhados por parte da população pobre que interioriza a imagem negativa que a sociedade constrói dela.

O deslocamento de responsabilização da pobreza material extrema, do plano macro para o plano micro, resulta em sentimentos de não pertencimento a um grupo social mais amplo, o que compromete diretamente a construção de uma autoimagem como sujeitos de direito. Com este argumento, os autores defendem que políticas sociais públicas não devem ser entendidas como atos de caridade ou mero assistencialismo, mas sim, instrumentos de cidadania, cujo objetivo maior é promover certa coesão social, no sentido de todos se sentirem pertencentes a um ente coletivo. Explicitam como a cisão social entre pobres, pobres extremos e ricos, os torna estranhos em um mesmo 
território, desabilitando o pressuposto filosófico de que todos os membros de uma comunidade são merecedores de direitos, consideração e respeito de forma igual.

No capítulo 3, destinado às apresentações das entrevistas, observa-se a preocupação dos autores em manter, na escrita, as vozes das beneficiárias. Desta forma, os fragmentos selecionados apontam para uma fluência própria da oralidade e uma narrativa viva em que é quase possível ouvir as mulheres, suas entonações, angústias e silenciamentos. De forma sensível, os autores expõem as dificuldades do campo, materializadas, tanto na questão do acesso a estas zonas territoriais quanto na preocupação em formular as questões respeitando o código linguístico de cada uma das entrevistadas. Metodologicamente, os autores dividiram as entrevistas em quatro blocos distintos: (1) composição do núcleo familiar; (2) destino do dinheiro da bolsa; (3) opinião sobre o Programa e seus efeitos; e (4) atitudes perante a política e direito do voto.

O capítulo 4 se ocupa sobre o entendimento da pobreza em uma visão pluridimensional, pois ainda que a renda se apresente como aspecto fundamental na compreensão deste fenômeno, a pobreza engloba uma série de outras composições. Um dos autores chamado para dar maior entendimento à questão é Amarthya Sen e, em sua teoria de capabilities, nesta perspectiva, os pobres são aqueles destituídos, sim, de renda mínima - pobreza primária - mas são também aqueles em que a ausência de Estado lhes mantêm por longos períodos de tempo, sem os acessos aos bens e serviços que impedem a produção de capabilities, inviabilizando a mobilidade social. O capítulo alia a teoria de Sen à peculiaridade da pobreza brasileira com seu passado escravocrata, com seu presente de imensa concentração da riqueza e um futuro com pouca perspectiva ética, diante de um país em que se mantêm preconceitos de classe.

Dinheiro e autonomia são temas do capítulo 5 que se inicia com uma afirmação importante, "depois de cinco anos de andanças pelas regiões mais pobres do Brasil [...] pode-se afirmar que o programa Bolsa Família produz mudanças significativas na vida das pessoas destinatárias deles." (REGO; PINZANI, 2013, p. 197-198). Georg Simmel, e sua sociologia do dinheiro, são utilizados para aprender as relações entre dinheiro e autonomia individual e, Stuart Mill e Seyla Benhabib, para as relações de família e dominação, analisando, sobretudo, o empoderamento das mulheres que são, pelo 
programa, as beneficiárias da bolsa. As múltiplas funções do dinheiro, que permite além das aquisições materiais, a liberdade de escolha, o poder dissolvente encontrado nas teorias de Marx e Simmel, são bem dimensionados com os relatos das mulheres beneficiárias do Bolsa Família e explicitam também que "mesmo no seu minimalismo, o programa Bolsa Família pode ser visto como política de urgência moral." (REGO; PINZANI, 2013, p. 218).

Nas considerações finais são abordadas as noções de renda monetária e autonomia cívica e política, demonstrando as confusas noções que as mulheres entrevistadas têm a respeito do voto e do direito a elas concedidos, ao mesmo tempo em que identificam no governo Lula o papel central na concessão da Bolsa, inúmeras vezes reconhecido por elas como uma ajuda, dada por alguém. Relembram os percursos da pesquisa, evidenciando o descompromisso dos poderes locais, que diminuem o impacto e aprofundamento de cidadania via o direito concedido no programa Bolsa Família, que inclui os beneficiários no corpo político e "Por esta razão são programas de cidadania no sentido mais próprio do termo." (REGO; PINZANI, 2013, p. 226).

No que tange a renda monetária e autonomia ético-moral, os autores estabelecem um primordial paralelo entre a noção de incompletude que atinge as mulheres sem escolhas; o compromisso do lugar de mãe lhes induz, na parca autonomia, que a bolsa Ihes concede um exercício imprescindível, de melhor alimentar, vestir e comprar material escolar para seus filhos. São capabilities do cotidiano elementares para a dignidade humana. Assim, o Bolsa Família "resulta na humanização de seus destinatários, a qual representa um passo necessário e decisivo no seu processo de autonomização." (REGO; PINZANI, 2013, p. 228). Com menos vergonha da sua condição de indigência, podem iniciar um processo de fala de si e de suas condições, marcando um outro espaço de cidadania. Registram a experiência brasileira de organizar o programa Bolsa Família, frente a uma equivocada noção de globalização que retira do Estado suas atribuições. Consideram um passo decisivo, pois entendem que "somente por meio do Estado podem aqueles processos distributivos necessários para a construção de uma comunidade cidadã mais justa." (REGO; PINZANI, 2013, p. 232). E por fim, apontam para a necessidade de outro paradigma de referência ao se tratar com os pobres. É necessário eliminar os 
preconceitos que os compreendem como resultado de falha moral e desordem pessoal, preconceito bastante visível no debate que se estabeleceu no país sobre o programa em pauta, etiquetando-o de paternalista. Esta densa pesquisa, demonstra que o programa é uma fenda pequena, mas com uma imprescindível abertura para o estabelecimento de novas realidades. A nação de sujeitos iguais e livres, preceituada em nossa Constituição, requer sim, ações redistributivas de renda, que permitam transformar os sofrimentos de inúmeras gerações de brasileiros em esperança de tempos mais justos.

Recebido em: 13/04/2015 Aprovado em: 12/05/2015

Universidade do Estado de Santa Catarina - UDESC Programa de Pós-Graduação em Educação - PPGE Revista Linhas

Volume 16 - Número 31 - Ano 2015 revistalinhas@gmail.com 